\title{
What Am I Reading?: Article-style Native Advertisements in Canadian Newspapers
}

\author{
Sarah E. Cornwell and Victoria L. Rubin \\ Language and Information Technology Research Lab (LIT.RL) \\ Faculty of Information and Media Studies \\ University of Western Ontario, London, Ontario, CANADA \\ scornwel@uwo.ca, vrubin@uwo.ca
}

\begin{abstract}
Native ads are ubiquitous in the North American digital news context. Their form, content and presentational style are practically indistinguishable from regular news editorials, and thus are often mistaken for informative content by newsreaders. This advertising practice is deceptive, in that it exploits loopholes in human digital literacy. Despite this, it is flourishing as a lucrative digital news advertising format.

This paper documents and compares the 2018 Canadian news editorial writing and advertising practices in an effort to highlight their similarities and differences for potential automatic detection and categorization. We collected 10 native ads and 10 editorial pieces from 4 Canadian newspapers. The 80 analyzed articles consisted of 40 native ads contentmatched to editorials in the same newspaper. The individually-matched pairs and overall practices in the 2 groups were content-analyzed and compared. Native ads did not differ much from editorial articles in content but were likely to be surrounded by different types of advertising. In addition, advertisement labelling practices were inconsistent across national papers. We call for increased efforts in regulation and automatic detection of convert advertising by a more nuanced categorization and their more explicit labeling in the digital news.
\end{abstract}

\section{Introduction}

As North American Internet users become used to seeing ads in the same places and formats, they develop what is known as "ad avoidance" or "banner blindness" [1]. When readers become accustomed to seeing ads in the same places, they actively avoid looking there, and internet advertisements become less effective [1]. Advertisers are left with a dilemma. Do they make their advertisements more obnoxious and noticeable: pop- ups, blinking, noisy ads? Or do they make their ads more deceptive, unnoticed and therefore un-avoided? Native advertisements represent a step towards the latter choice, creating a genre of covert advertising alongside product placement and advergames (a portmanteau of "advertising" and "games"). While creators tout them as being content-like and entertaining for consumers, the difficult truth is that these ads work more effectively when readers do not realize that they are looking at an advertisement [2, 3]. And readers are frequently deceived - labelled native advertisements are recognized as advertising by as little as $7 \%$ of readers [4]. This is because modern native advertisements go one step past the "advertorials" which have been present in newspapers for decades.

This paper examines article-length native advertisements published in online newspapers. Today's native advertisements do not just mimic the form of the surrounding articles, they also mimic both their content and style [1]. A content analysis by Warnick [5] found that advertising articles from the New York Times, Wall Street Journal, Washington Post, and Slate mirror the content of traditional journalism.

\section{Literature Review}

\subsection{Background}

Native ads are also growing in popularity across online outlets worldwide: they are ubiquitous in social media and increasingly present in online newspapers. In Canada, as in the US, newspapers have opened their own Native Advertising production houses - for instance, Postmedia's Polar and The Globe and Mail's Globe Edge. Newspaper watchdogs have raised ethical concerns; native ads have been called "fraudulent" and "a form of prostitution" by Canadian magazine editors [6]. Concerns lie not just with their deceptive quality, but also because appearing as news means advertisers 
may put pressure on editorial news coverage to avoid controversy and sell with sensationalism [7, 8]. There are also threats of a "brain drain" from editorial to advertising, as creating native advertising requires journalistic talent. In 2014, The Globe and Mail attempted to mandate that its editorial journalists produce native advertising (called "Branded Content" by the paper) [9]. This choice drew ire from media watchdogs [10] and almost caused an editorial staff strike [9]. This event is but one in a changing journalism landscape where the cracks in the traditional wall between the editorial and advertising departments are ever widening. A 2016 survey by the Native Advertising Institute estimates that over $40 \%$ of publishers who publish native ads use their editorial team to write them [11]. This is a clear example of the wall dissolving, and the "sacred" editorial merging with the "profane" advertising [8]. Despite these ethical concerns, native advertising is growing in popularity [12]. Sponsored content, which includes native ads, was identified as 2018 's most important digital revenue stream by $42 \%$ of online publishers surveyed by Reuter's Digital News Project [12]. Wojdynski \& Golan [13] go so far as to call native ads the "primary driving engine of the Internet marketing economy", and report on a prediction of native ad spending at $\$ 21$ billion by 2018 .

There has been some previous work in classifying native advertising. Table 1 shows the relation of the classifications proposed by Wojdynski [1] and the
Interactive Advertising Bureau (IAB: a prominent advertising media coalition that develops industry standards for Europe and US, headquartered in New York) [14]. Wojdynski's organization has three elements. Sponsored content is written and designed to mimic the form of regular content. Sponsored articles and advertorials in a newspaper would fit into this class. Sponsored hyperlinks appear to link to other pages within the site but are ads for other sites. Taboola and Outbrain are two popular providers of this type of advertising widget. Sponsored Social Media posts are paid for posts on social media. They appear in the users' regular content stream but are for products or companies that the user has not chosen to follow. The IAB's classes are more detailed. In-feed units includes both Sponsored Content and Sponsored Social Media posts: any post that appears truly native to the site. Custom Content is similar, but it could be platform specific (e.g., sponsored playlists on Spotify) or otherwise outside the spaces where users are used to encountering ads. Recommendation Widgets aligns most closely to Wojdynski's Sponsored Links. The IAB also includes specific categories for advertisements that are recommended after searching or while browsing (Paid Search Listings and Promoted Listings). Finally, the IAB has added a category for ads which adhere to their ad container system (In-ad). The article-style type of native ad investigated here would fit into the "custom content" or "sponsored content" classes.

Table 1. Types of native advertising in the Wojdynski (2016) and IAB classification schemes

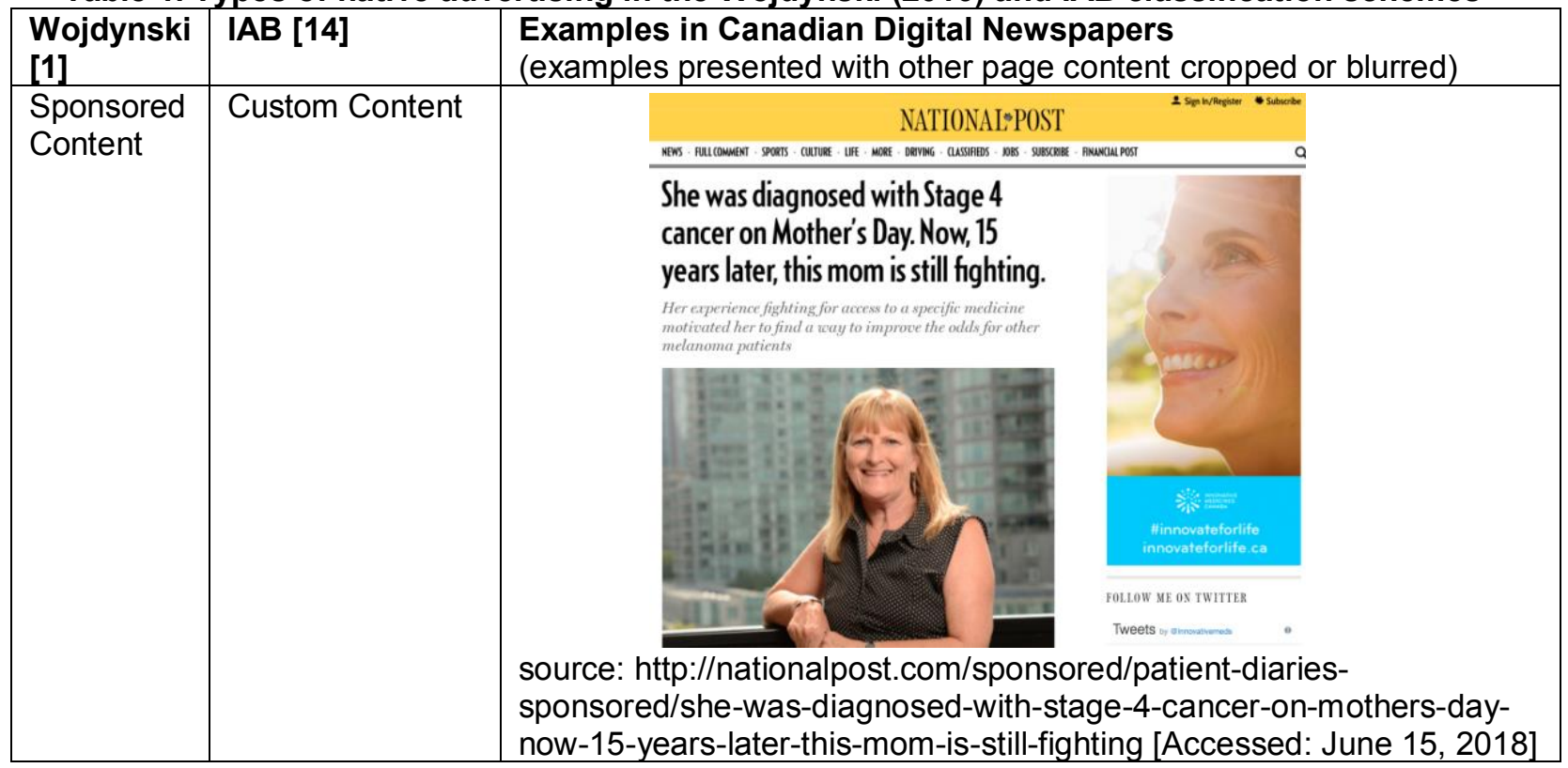




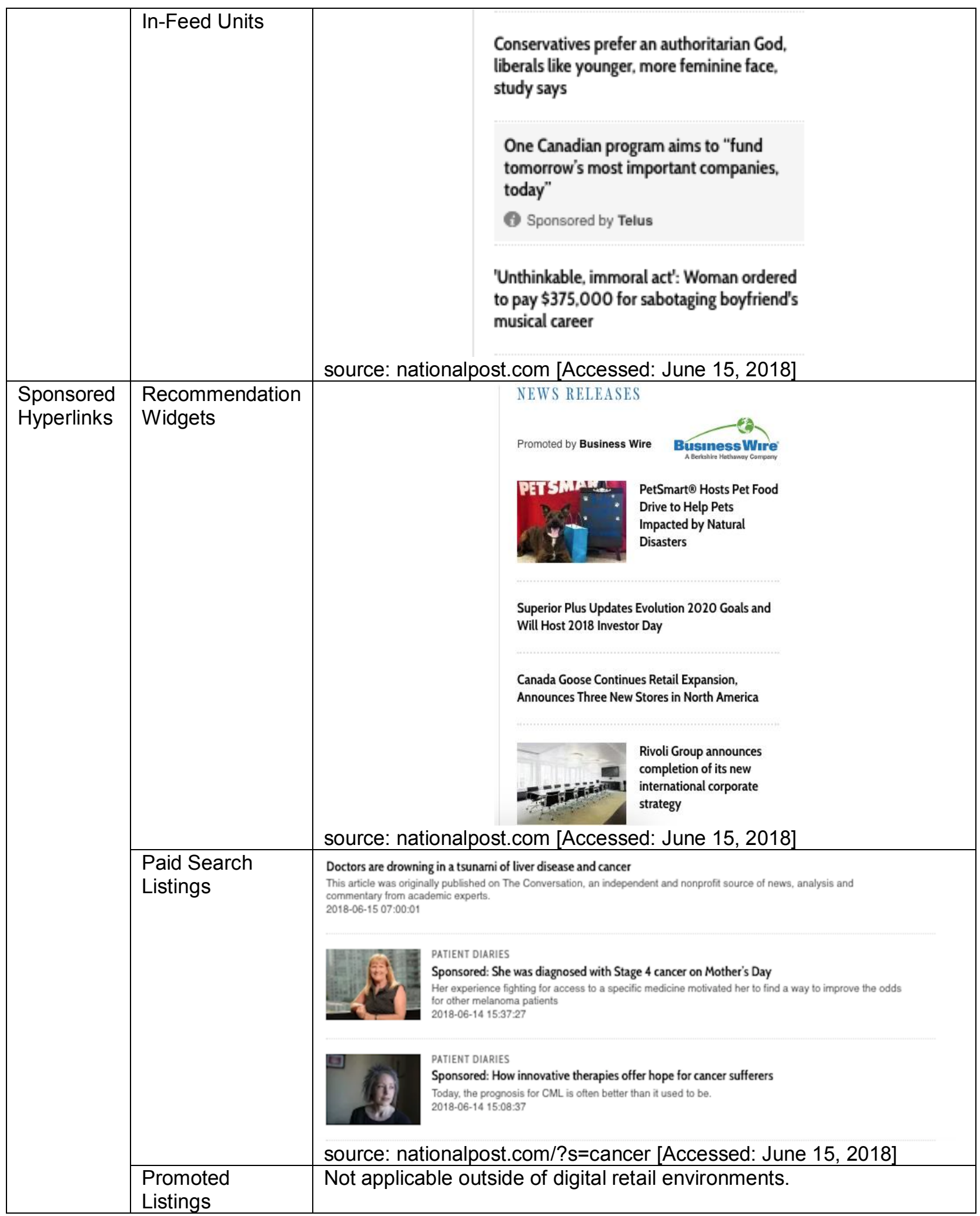




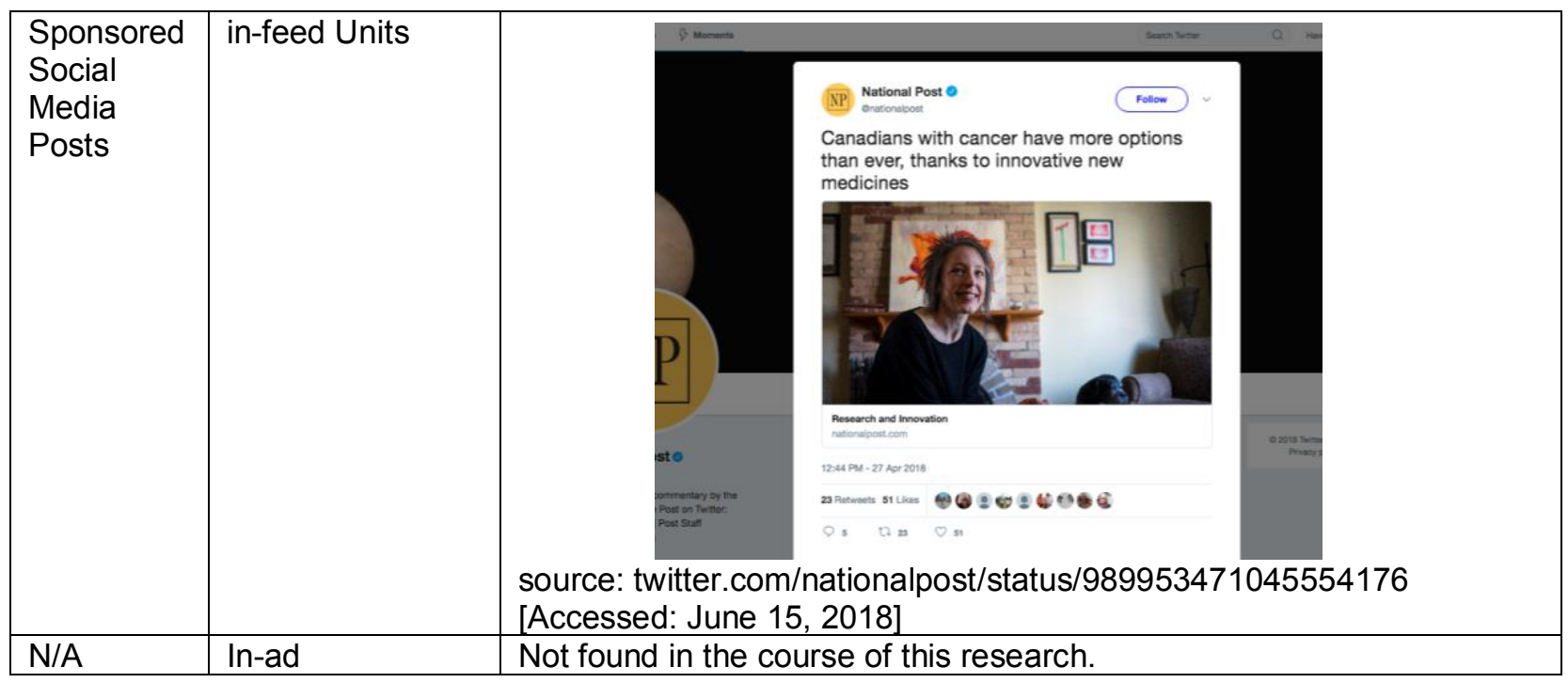

Neither scheme seems ideal. Wojdynski's scheme seems overly simplistic, while separating social media content from other content for unexplained reasons. The Interactive Advertising Bureau's scheme is appropriate for their needs (i.e., ad sales). However, as Wojdynski [1] notes, the IAB scheme lacks a supporting theory and its categories do not reflect reader interaction or ad content itself. Additionally, the "custom content" category acts as a catch-all or miscellaneous category. It is not specific enough for rigorous classification. Despite these weaknesses, the IAB scheme has been used in research, see the content analysis by Conill [15] for a recent example. Both schemes organize advertisements based on their style rather than content advertisements that are produced by advertisers, publishers, or editorial groups are treated identically. This means that the likelihood of deception (or other reader attributes) are not meaningful classifiers in either scheme.

\subsection{Reader Deception}

How do readers interpret covert advertising like native ads? Previous research has applied theory to native advertisement recognition and interpretation. Schema Theory (also called Framing theory in Communications research [16]) has been used to explain uneven recognizing of native advertisements. The Persuasion Knowledge Model (PKM) posits that all people have an idea of what frames or schemata are used by persuaders [17]. This Persuasion knowledge is updated through experience across one's life. When encountering a situation that one recognizes as persuasive, one activates their persuasion knowledge in concert with their knowledge of the topic at hand (Topic knowledge), and of the convincer (Agent knowledge) [17].

For example, when Helen reads the newspaper, she will activate her persuasion knowledge in the classifieds section. This persuasion knowledge, along with her agent knowledge of newspaper ads and topic knowledge of jobs, will let Helen use persuasion coping behaviors to decide which job ads are legitimate or scams. However, if Helen does not realize that some job ads can be illegitimate, she will not activate her persuasion knowledge, and she will not be able to access her persuasion coping behaviors. Instead, she would likely assume that what she reads is true. Truth bias experiencing situations as truthful by default - is a common cognitive heuristic [18]. The inactivation of persuasion knowledge has been hypothesized to be the working model of covert advertisements $[19,20]$. When readers do not realize that they have encountered an advertisement, they do not "defend" against the persuasion using their coping behaviors, and so are more easily convinced [20].

The behavior of readers after realizing that the content was advertising has also been researched, mostly using public relations theory. Sweetser et al. [21] used public relations theory, specifically the Organization-Public Relationship (OPR), to explain how readers were affected by native advertising disclosure. Unethical behavior damages OPRs, while being credible, trustworthy, and providing useful information strengthens OPRs [21]. This study found that the negative affect from the lack of transparency was applied to the advertised brand (Netflix) rather than the publisher (The Wall Street Journal (WSJ)). However, other researchers [20] have found that publishers (The New York Times (NYT), WSJ, and an invented publisher) can also hurt their reputation by 
using covert native advertisements. Deception is likely to be a poor long-term strategy for publishers as consumers have more positive attitudes towards advertisements where sponsor relationships are more transparent [22]. As more readers begin to add information about native advertising to their persuasion knowledge, publishers will likely begin to erode reader trust.

After encountering the many ethical and reputational concerns about native advertising, it can be surprising to learn that this is an ad format that is growing in popularity. The reason is, as it often is, with budgets. The transition to digital has been devastating to advertising and circulation newspaper incomes [8]. Most publishers price native advertisements higher than traditional advertising formats [11], so they are seen as an effective way to boost ad sales. The custom nature of article-style native advertisements also allows for advertisers to communicate more complex messages and have more interaction with readers (through comments, social media widgets, etc.). These benefits have fueled the current growth of the format.

\section{Research Question}

Given the current rise of the popularity of the format and style of the native ads,

1. Do native advertisements differ from editorials in how they are labelled, written and formatted in the Canadian digital news context?

We investigate this question in 3 different ways. First, by addressing the manner with which native ads are labeled across a sample of Canadian digital newspapers. Second, we comparatively analyze and discuss the differences in content and presentation style by comparison with the regular editorial articles. This comparison was done with content-matched pairs of advertisement and editorial articles. Lastly, we consider the differences in the context of the digital news layouts in which the advertisements and editorials appear. These three facets of labeling, content, and context represent the likely locations for cues that readers will use to identify advertising content.

The overall purpose of this research is to document the current practices in native ads writing and discuss their potential perceptions by digital news readers in Canada in 2018, specifically in terms of their potential deceptiveness. The underlying hypothesis is that if the native ads do not appear to be different in labeling, content, or context, then their current style is less obviously apparent to the reader and is thus deceptive. In short, Native advertisements that appear too alike editorials may be mistaken for editorials. This is subject to further experimentation and observation. These creative advertising practices may continue to develop over time and become less obvious in order to avoid being easily detected by readers.

\section{Methods}

For this study, native advertisements were collected from the Canadian English-language newspapers with the highest circulation. Two national papers were chosen (The Globe and Mail; The National Post) as well as the highest circulating paper from each of Canada's two largest cities (The Toronto Star; The Vancouver Sun). Each native ad was content-matched to an editorial article from the same paper. In total, 10 native ads and 10 editorial pieces were collected from each of the four newspapers, for a total of 80 articles.

The advertisements were found by browsing the newspapers' home page without an ad-blocker. Native ads are commonly found in fashion, travel, and other consumption-centric sections, so these areas were also browsed. Links to native ads were also found via sidebar banner ads. If no native advertisements were found from the homepage or browsed sections, searches were done for terms like "ad", "native ad", and "advertorial".

Each newspaper was paired with a topic based on the Native ads that were present at the time: The Toronto Star's advertisements covered building development and home improvement; The Vancouver Sun, tourism and real estate; The Globe and Mail, financial technology and charity, and The National Post, fashion and health. The editorial articles collected from each paper were on the same topic (See Table 2). For example, The Toronto Star's native ads on development were paired with editorials on development. "Development: What's in it for you", a native advertisement for the Building Industry and Land Development Association (BILD) was paired with the editorial article "Toronto considering doubling development charges for new projects".

Each article was read and content analyzed by a single coder (first author). Each advertisement was checked to see if a label was present. If a label was present, the location, readability (color and font size), and content of the label was recorded. Every article was checked for a byline, and the type of author (staff reporter, corporation, ad studio, or no author) was recorded. Next, the entire article was read, and the overall emotional affect (positive, negative, neutral) of the article was recorded. The grammatical moods used in the article were also recorded. The English grammatical moods that were recorded are indicative (e.g., She went to the store.), imperative (e.g., Go to the store.), conditional (e.g., If she goes to the store, I will go too.), and interrogative (e.g. Did she go to the store?). 
The type of image (e.g., stock or file photo, original photo, drawing or cartoon, labelled diagram, video, or not illustrated) was also recorded for each article. If more than one image was included, each was counted separately. The other content on the page was also recorded. These included different advertisement formats including banners, pop-ups, and background "wallpaper" images, among others. If more than a single instance of a type of advertisement was found, each was recorded separately.

The frequency of each category was totaled. Chisquare tests $(\alpha=.95)$ in $\mathrm{R}$ were used to test for significant differences in the frequency of affect, grammatical mood, image types, and ad types used in the two types of article. While the advertisements were pseudorandomly sampled, the editorial articles were contentmatched to them. This means that the articles are likely to be more similar than two randomly sampled articles (one advertising, one editorial) would be. The chisquare test is likely to underestimate the presence of statistical differences between the two article types.

Table 2. Examples of headlines and topics collected from each newspaper

\begin{tabular}{|l|l|l|l|}
\hline Paper & $\begin{array}{l}\text { Topic } \\
\text { (advertiser) }\end{array}$ & Advertising Headline & Editorial Headline \\
\hline $\begin{array}{l}\text { The Globe } \\
\text { and Mail }\end{array}$ & $\begin{array}{l}\text { financial } \\
\text { technology } \\
\text { (Interac) }\end{array}$ & $\begin{array}{l}\text { What's in store for the future of } \\
\text { mobile payments? }\end{array}$ & $\begin{array}{l}\text { Apple in talks to launch money- } \\
\text { transfer service: report }\end{array}$ \\
\hline $\begin{array}{l}\text { The } \\
\text { Toronto } \\
\text { Star }\end{array}$ & $\begin{array}{l}\text { building } \\
\text { development } \\
\text { (BILD) }\end{array}$ & $\begin{array}{l}\text { Transit considered key to creating } \\
\text { 'quality, complete, investment-ready } \\
\text { communities' }\end{array}$ & $\begin{array}{l}\text { Need for GTA development } \\
\text { competing with Greenbelt Act }\end{array}$ \\
\hline $\begin{array}{l}\text { The } \\
\text { Vancouver } \\
\text { Sun }\end{array}$ & $\begin{array}{l}\text { tourism } \\
\text { (Whistler }\end{array}$ & $\begin{array}{l}\text { Send off the season at the World Ski } \\
\text { and Snowboard Festival }\end{array}$ & $\begin{array}{l}\text { Finding the perfect BC Beach } \\
\text { may mean heading out of town }\end{array}$ \\
\hline $\begin{array}{l}\text { The } \\
\text { National } \\
\text { Post }\end{array}$ & $\begin{array}{l}\text { fashion } \\
\text { (Indochino) }\end{array}$ & $\begin{array}{l}\text { The spring trifecta: Three ways to } \\
\text { diversify your suit collection }\end{array}$ & $\begin{array}{l}\text { Say goodbye to luxury yoga } \\
\text { pants: Fashion wants you to try } \\
\text { harder this fall }\end{array}$ \\
\hline
\end{tabular}

\section{Results}

The results section is split into 3 sub-sections; 1 for each of the foci named in the research question. The first, labelling, reports on how labels were applied to native advertisements in the four newspapers. The second, content, reports on the stylistic factors of grammatical mood and affect. The use of these stylistic factors in native advertisements was compared to their use in editorial articles. Finally, the context subsection reports on the use of images and advertisements in the two article types.

\subsection{Labelling}

Labelling practices were standard within each paper but differed between them. No two papers used the same language to identify native advertisements - even the Vancouver Sun and the National Post, which are both produced by PostMedia, used different label text. The location of the labels was consistent across all papers, appearing directly above the headline. A summary of each paper's labelling practices is presented in Table 3.

Overall, labels were less noticeable than other text on the page. They were usually presented in a smaller font, or in a color combination with less contrast than the body text (black on white). The FTC recommends that label text color "contrast strongly with the background" and "be large and visible enough for consumers to readily notice them" [23]. While the disclosures were reliably in a noticeable location above the headline - they were also much smaller than the headline. This combination of factors means that the labels lacked prominence overall.

The clarity of the label text is also suspect. The FTC recommends that labels use the word "ad" or "advertisement" so that their promotional nature is clear to readers [23]. Industry groups like the IAB have similar labeling recommendations [14]. None of the sampled advertisements used the word "ad" or "advertisement" in the label at the top of the article page. The Globe and Mail, however, did include an additional disclaimer after the body text stating that the "content was produced by The Globe and Mail's Globe Edge Content Studio, in consultation with an advertiser". Overall, the clarity of advertising labels was also against the FTC's recommendations, as using "sponsored" does not clearly communicate the degree to which advertisers had control over the content. 
Table 3. Native advertising labelling practices

\begin{tabular}{|c|c|c|c|c|c|}
\hline \multirow[t]{2}{*}{ Newspaper } & \multirow[t]{2}{*}{ Text } & \multirow[t]{2}{*}{ Location } & \multicolumn{2}{|c|}{ Readability } & \multirow{2}{*}{$\begin{array}{c}\text { Example } \\
\text { (cropped to include only label } \\
\text { and headline) }\end{array}$} \\
\hline & & & Color & $\begin{array}{l}\text { Font } \\
\text { Size }\end{array}$ & \\
\hline $\begin{array}{l}\text { The Globe } \\
\text { and Mail }\end{array}$ & $\begin{array}{l}\text { Sponsor } \\
\text { Content }\end{array}$ & $\begin{array}{l}\text { above the } \\
\text { headline }\end{array}$ & $\begin{array}{l}\text { grey text on } \\
\text { pastel } \\
\text { yellow or } \\
\text { blue } \\
\text { horizontal } \\
\text { bar }\end{array}$ & $\begin{array}{l}\text { similar } \\
\text { to body } \\
\text { font size }\end{array}$ & $\begin{array}{l}\text { What's in store for the future of } \\
\text { mobile payments? }\end{array}$ \\
\hline $\begin{array}{l}\text { The Toronto } \\
\text { Star }\end{array}$ & $\begin{array}{l}\text { Partner } \\
\text { Content }\end{array}$ & $\begin{array}{l}\text { above the } \\
\text { headline }\end{array}$ & $\begin{array}{l}\text { blue text on } \\
\text { white } \\
\text { horizontal } \\
\text { bar }\end{array}$ & $\begin{array}{l}\text { similar } \\
\text { to body } \\
\text { font size }\end{array}$ & $\begin{array}{l}\text { Partner Contentsuilding complete communities } \\
\text { Our neighbourhoods are } \\
\text { intensifying }\end{array}$ \\
\hline $\begin{array}{l}\text { The } \\
\text { Vancouver } \\
\text { Sun }\end{array}$ & $\begin{array}{l}\text { Presented } \\
\text { by } \\
\text { [advertiser] }\end{array}$ & $\begin{array}{l}\text { above the } \\
\text { headline }\end{array}$ & $\begin{array}{l}\text { black text } \\
\text { on white } \\
\text { background }\end{array}$ & $\begin{array}{l}\text { similar } \\
\text { to body } \\
\text { font size }\end{array}$ & $\begin{array}{l}\text { The death of retail storefronts } \\
\text { greatly exaggerated }\end{array}$ \\
\hline $\begin{array}{l}\text { The National } \\
\text { Post }\end{array}$ & $\begin{array}{l}\text { This } \\
\text { content is } \\
\text { sponsored } \\
\text { by } \\
\text { [advertiser] }\end{array}$ & $\begin{array}{l}\text { above the } \\
\text { headline }\end{array}$ & $\begin{array}{l}\text { black text } \\
\text { on white } \\
\text { background }\end{array}$ & $\begin{array}{l}\text { smaller } \\
\text { than } \\
\text { body } \\
\text { font size }\end{array}$ & $\begin{array}{l}\text { She was diagnosed with Stage } 4 \\
\text { cancer on Mother's Day. Now, } 15 \\
\text { years later, this mom is still fighting. }\end{array}$ \\
\hline
\end{tabular}

\subsection{Content}

The content of native advertisements and editorial pieces did not differ very much in terms of affect and grammatical mood. Generally, the analyzed articles tended towards a positive affect, with about half of editorial pieces $(n=21)$ and three in four advertising pieces $(n=31)$ having an overall positive affect. The chisquare test approached significance $\left(\chi^{2}=5.51\right.$, d.f. $=2$, $\mathrm{p}=0.06$ ). Despite this near significance, differences in affect were more salient across topics than across article types, as the health and home renovation topics were more negative overall. This is likely due to the negative emotions associated with illness and natural disasters (e.g., flooding) which were highlighted in those topics.

Both article types also used grammatical mood similarly, favoring indicative mood in about half of all articles (editorial $n=20$, advertisement $n=22$ ). A chisquare test found the difference between the two article types was significant $\left(\chi^{2}=10.55\right.$, d.f. $\left.=3, p=0.01\right)$. However, the small number of articles $(n=3)$ using the interrogative mood means that the test may be unreliable. Overall, editorial articles used more types of grammatical mood per article and used the conditional and interrogative moods more often. Advertising pieces were generally limited to the indicative and imperative moods. This small difference was predictable. Journalism is more likely to question and predict (applications of the conditional and interrogative moods), while advertising was more likely to direct reader action through use of the imperative mood.

Overall, the surface-level stylistic similarities between editorial and advertising content were more salient than their differences. It is unknown to what extent readers may use these relatively superficial stylistic differences in their assessments of the persuasive nature of content. However, the high levels of similarity mean that any readers who do use this type of stylistic cue may be confused or deceived by the native advertisement copy that generally reads very similarly to that found in editorial articles. 


\subsection{Context}

The text of native advertisements and editorial articles were surrounded by different types of content. Both article types were surrounded by standard web advertising in the form of banner ads at the top, bottom, and left side of the page. Other advertisements that were included were inter-article video ads, floating footer bars, and flyers that pop-up when the cursor hovers over them. A chi-square test found that the frequencies of advertising types used in both article types was not significantly different $\left(\chi^{2}=5.04, \quad\right.$ d.f. $\left.=6, \quad p=0.54\right)$. However, the content of the advertisements varied greatly between the two types. The advertisements included alongside native advertising content were almost exclusively advertisements for the article's advertiser - the only exception were the Vancouver Sun's Travel themed pieces. The inclusion of only a single advertiser on the page was a good indication that the article was a native advertisement. These thematic ads are called "companion" ads [22].

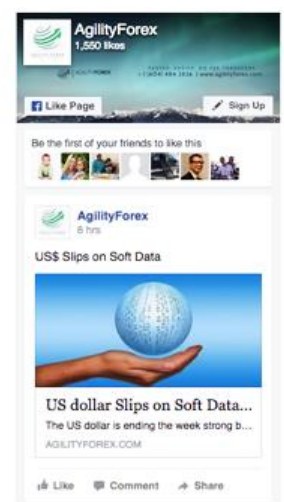

For more tips on how to upgrade your wardrobe this spring, visit an INDOCHINO showroom near you or browse their full collection online.

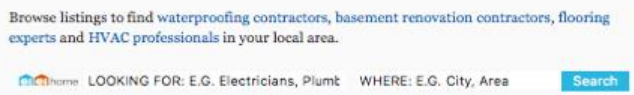

Figure 1. Example of a social media widget, specialty search bar, and hyperlinks included in native advertisements

Native advertising pages also included specialty content which were not tallied in the advertisements count. These included interactive article elements like Facebook and Twitter social media widgets, specialty search bars for advertisers' sites, and hyperlinks within the article that take readers to the advertiser's site. Examples of these elements are included in Figure 1. None of the investigated editorial pieces included these types of specialty interactive elements. The singleadvertiser content of the surrounding advertisements, as well as the presence of these specialty elements, was a consistent and salient difference between editorial and advertising content.
The surrounding advertisements can also be a site for further confusion. Editorial pieces commonly have lists of links to other editorial articles in the sidebar. In article-style native advertisements, however, these links are replaced by those which direct to the advertiser's websites. These "recommendation widgets", to use the IAB classification term, look very similar to editorial recommendation elements. An example demonstrating the visual similarity of these elements included in Figure 2. This type of mimicry is likely to deceive users who are accustomed to finding links to other journalistic pieces in article sidebars.

The type of images accompanying each article was also analyzed. There was little difference in the type of images used, with both types of articles generally including a single photo. This conclusion is supported by the chi-square test, which found no significant difference $\left(\chi^{2}=1.88\right.$, d.f. $\left.=2, p=0.39\right)$. The frequencies for no photo, video, and diagrams were omitted from the chi-square test because each cell contained only one case. Photos in advertising pieces were often credited to the advertiser, though photo credits were irregularly included overall. It was difficult to determine how much of the photography consisted of stock or file photos, versus original photography. Overall, the use of images was very similar between the two groups.

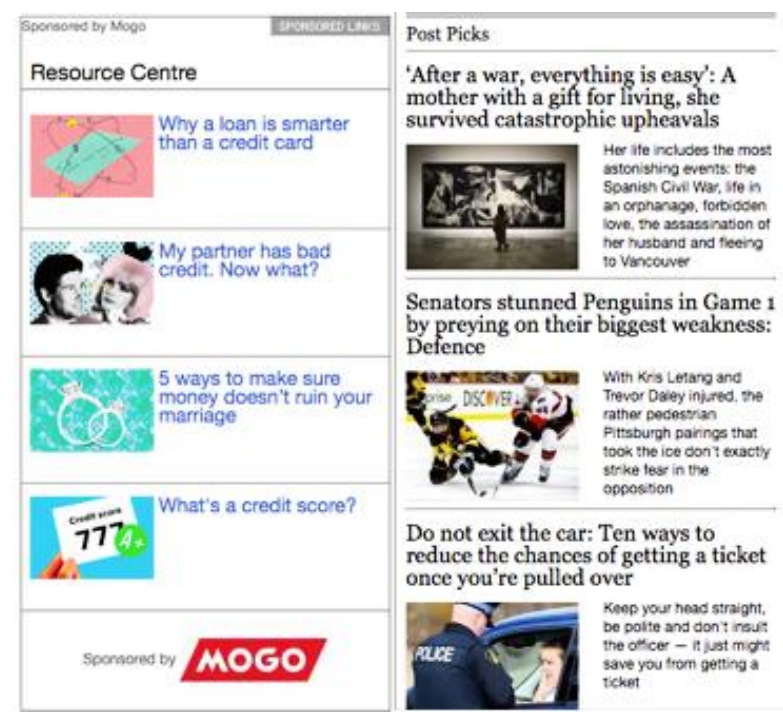

Figure 2. Two recommendation elements from The National Post: on the left, an advertisement; on the right, editorials.

\section{Limitations and Future Directions}

The analyses conducted in this study only scratch the surface of the potential points of difference between native advertisements and editorials. The content-level features reported in this study are particularly surface- 
level (i.e., visual, typographic, lexical), and investigations of deeper semantic-level features are warranted. The low frequency in some of the investigated categories (interrogative mood, some image types) also means that the significance of the chisquare tests may be unreliable. We also acknowledge that chi-square tests are likely to underestimate statistical differences because of the non-random nature of article selection. Further research on this data set may uncover additional cues for readers to use in differentiating this article types. More intensive analyses using natural language processing or machine learning techniques are likely to uncover additional linguistic patterns in these news article types, especially if applied to a larger sample size and a greater variety of topics. The data set is available for research and will be published at http://victoriarubin.fims.uwo.ca/research/.

\section{Discussion and Conclusion}

This research aimed to comparatively analyze the labeling, content and context in which native ads in Canadian digital news are being presented to news readers. Our initial suspicion was that one mechanism for the success of native ads results from the fact that they are practically undistinguishable from editorials in the same paper. This suspicion was confirmed along the 2 parameters: content and context. In addition, while the labeling of native ads is present, it is not standardized across news outlets and thus may possibly increase the chance of newsreaders ignoring the varying inconsistent labels. The small size and low contrast of labels may increase reader confusion. The grammatical moods and emotional affect used in the sample editorials and native ads were very similar, as were the types of images included in both native advertisements and editorials. These stylistic similarities help to explain the high levels of reader confusion found in other studies (e.g., [3, 4, 20, 22]).

However, there were some salient differences that could be used to help readers recognize advertising content more quickly. The advertisements surrounding native advertising articles were almost exclusively associated with a single advertiser. A recent study by Campbell and Evans [22] found that readers already use this type of advertising-based cue to recognize advertising content at similar rates to traditional textbased labels. As newsreaders become more familiar with news articles as potentially deceptive environments, this type of cue is likely to become part of their persuasion coping behaviors.

Currently, approximately one-third of readers are being deceived, and they cannot rely on current technological solutions for aid. While ad blockers partially succeed in blocking native ads, the closer the ads are to the editorials in form and content, the harder they will be to pick up and block automatically in this race for profit. In addition, adblockers do successfully block banner ads, making the commercial nature of article-style native advertisements less apparent by removing these major cues. In this way, the use of adblockers can ironically make article-style native ads even more deceptive.

This problem is only likely to grow worse as news articles are increasingly encountered outside of newspapers' sites and are instead found on social media sites and distributed publishing platforms like Google News. These sources are increasingly where North American web users find their news: Reuters reports that in almost all countries in 2017 more people relied on social media rather than newspapers as a news source [12]. Article-style native advertisements that are viewed using social media or other forms of distributed publishing lose their two proven cues: labels and companion advertisements. Even newspapers omit labels when promoting these articles through their social media, as seen in the example included in Table 1. This will likely result in even greater proportions of readers being deceived by this type of content.

To better protect digital news readers, native ads require stricter oversight and regulation from governmental bodies. Clearer and more explicit labeling practices are needed in Canada. Educational campaigns to explain the current trends in advertising would also benefit newsreaders. Experts in natural language processing, data-mining, and specifically automated deception detection could counter the current native ad practices (as well as other online deception) with automated detection, classification, and clearer labeling efforts [24]. Descriptive studies exemplified in the current research will enable predictive efforts for future detection of such deceptive practices.

We call for increased efforts in regulation of native ads in digital news environments and emphasize their deceptive powers. These advertisements are commonly passing for informative content written by impartial news staff. Meanwhile the computational community should take their own steps towards automated detection and more explicit labeling of covert advertising content, preferably with as nuanced a differentiation of the categories of such native ads as possible. The awareness of the latest creative native advertising techniques and varieties could ensure that news readers become digitally literate in the sense of their resistance towards the documented overt manipulations attempted by advertisers. 


\section{Acknowledgment}

This research was funded by the Government of Canada Social Sciences and Humanities Research Council (SSHRC) Insight Grant (\#435-2015-0065) awarded to Dr. Rubin for the project entitled Digital Deception Detection: Identifying Deliberate Misinformation in Online News.

\section{References}

[1] Wojdynski, B.W., "Native Advertising: Engagement, Deception, and Implications for Theory", in The New Advertising: Branding, Content and Consumer Relationships in a Data-Driven Social Media Era, R. Brown, V.K. Jones, and B.M. Wang, Editors. 2016, Praeger / ABC Clio.: Santa Barbara, CA, USA. p. 203-236.

[2] Schauster, E.E., P. Ferrucci, \& M.S. Neill, Native "Advertising Is the New Journalism: How Deception Affects Social Responsibility”. American Behavioral Scientist, 2016. 60(12): p. 1408-1424.

[3] Wu, M., et al., A Tale of Two Sources in Native Advertising: Examining the Effects of Source Credibility and Priming on Content, Organizations, and Media Evaluations. American Behavioral Scientist, 2016. 60(12): p. 1492-1509.

[4] Wojdynski, B.W. \& N.J. Evans, "Going Native: Effects of Disclosure Position and Language on the Recognition and Evaluation of Online Native Advertising". Journal of Advertising, 2015. 45(2): p. 157-168.

[5] Warnick, A., "A Qualitative Analysis of the Native Advertising Model with reference to the conventions of Journalism, in Journalism and Multimedia Arts". 2016, Duquesne University: Ann Arbor, MI. p. 36.

[6] Russell, N., Morals and the media ethics in Canadian journalism. 2 ed. 2006: Vancouver : UBC Press, c2006.

[7] King, R.P., "Popular Sources, Advertising, and Information Literacy: What Librarians Need to Know". The Reference Librarian, 2016. 57(1): p. 1-12.

[8] Carlson, M., "When news sites go native: Redefining the advertising-editorial divide in response to native advertising.” Journalism, 2015. 16(7): p. 849-865.

[9] Brunet, J. "On the Edge of Ethics". Ryerson Review of Journalism 2016 February 17, 2016 [cited 2017 January 19, 2017]; Available from: http://rrj.ca/on-the-edge-of-ethics/.

[10] Brown, J. "Leaked memo confirms that Globe and Mail wants journalists to write advertorials". Canadaland [News Brief] June 10, 2014; Available from:

http://www.canadalandshow.com/leaked-memo-confirmsglobe-and-mail-wants-journalists-write-advertorials/.
[11] Laursen, J. and M. Stone, Native Advertising Trends 2016: The News Media Industry, D. McMullen and L.C. Christopher, Editors. 2016, Native Advertising Institute International News Media Association. p. 47.

[12] Newman, N., Journalism, "Media and Technology Trends and Predictions 2017", in Digital News Project 2017. 2017, Reuters Institute for the Study of Journalism. p. 35.

[13] Wojdynski, B.W. and G.J. Golan, "Native Advertising and the Future of Mass Communication". American Behavioral Scientist, 2016. 60(12): p. 1403-1407.

[14] Interactive Advertising Bureau, The Native Advertising Playbook. 2013, Interactive Advertising Bureau. p. 19.

[15] Ferrer Conill, R., "Camouflaging Church as State". Journalism Studies, 2016. 17(7): p. 904-914.

[16] Entman, R.M., "Framing: Toward Clarification of a Fractured Paradigm". Journal of Communication, 1993. 43(4): p. 51-58.

[17] Friestad, M. \& P. Wright, "The Persuasion Knowledge Model: How People Cope with Persuasion Attempts". Journal of Consumer Research, 1994. 21(1): p. 1-31.

[18] Levine, T. R., Park, H. S., \& McCornack, S. A. "Accuracy in detecting truths and lies: Documenting the "veracity effect"”. Communication Monographs, 1999. 66(2), 125-144. doi:10.1080/03637759909376468

[19] Evans, N.J. \& D. Park, "Rethinking the Persuasion Knowledge Model: Schematic Antecedents and Associative Outcomes of Persuasion Knowledge Activation for Covert Advertising". Journal of Current Issues \& Research in Advertising, 2015. 36(2): p. 157-176.

[20] Amazeen, M.A. \& A.R. Muddiman, "Saving Media or Trading on Trust?" Digital Journalism, 2017: p. 1-20.

[21] Sweetser, K.D., et al., "Native Advertising as a New Public Relations Tactic". American Behavioral Scientist, 2016. 60(12): p. 1442-1457.

[22] Campbell, C. \& N.J. Evans, "The Role of a Companion Banner and Sponsorship Transparency in Recognizing and Evaluating Article-style Native Advertising". Journal of Interactive Marketing, 2018. 43: p. 17-32.

[23] Federal Trade Commission. "Native Advertising: A guide for businesses". Guidance 2015 December 2015 [cited 2017 November 16]; Available from: https:/www.ftc.gov/tipsadvice/business-center/guidance/native-advertising-guidebusinesses.

[24] Chen, Y., Conroy, N. J., \& Rubin, V. L. "News in an online world: the need for an automatic crap detector". Proceedings of the 78th ASIS\&T Annual Meeting: Information Science with Impact: Research in and for the Community, 2015, ISBN: 0-87715-547 